Perceptions of the Effectiveness of Training and Development of 'Grey-collar' Workers in the People's Republic of China

Kate Hutchings $^{\text {a* }}$, Cherrie J. Zhu ${ }^{b}$, Brian K Cooper ${ }^{c}$, Yiming Zhang ${ }^{d}$, Sijun Shao ${ }^{e}$

${ }^{\mathrm{a}}$ Department of Management, Monash University, Clayton, Australia; ${ }^{\mathrm{b}}$ Department of Management, Monash University, Clayton, Australia; ${ }^{\mathrm{c} D e p a r t m e n t ~ o f ~ M a n a g e m e n t, ~ M o n a s h ~}$ University, Caulfield East, Australia; ${ }^{\mathrm{d}}$ Institute for International Labor Studies, Ministry of

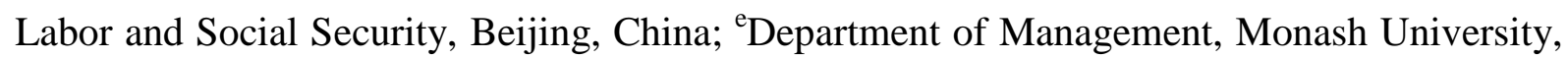
Clayton, Australia.

\footnotetext{
* Corresponding author. E-mail: Kate.Hutchings@BusEco.monash.edu.au
} 


\title{
Perceptions of the Effectiveness of Training and Development of 'Grey-collar' Workers in the People's Republic of China
}

\begin{abstract}
An important human resource development (HRD) implication of the People's Republic of China's (PRC) rapidly expanding economy has been the emergence of a critical shortage of grey collar workers (GCW). Though 'grey-collar' has been commonly used in the West to describe an aging population within the workforce, in China it refers to people who are neither white nor blue collar workers but technicians. The shortage of GCW constrains the PRC's economic and developmental sustainability and has been recognised in central and provincial government initiatives to increase training and development of employees within these fields. While acknowledged as a policy and organisational problem, there has been no research investigating what organisations are doing to develop these employees. Drawing upon a survey of 310 semi-skilled and skilled employees in Beijing, our findings suggest that while the surveyed organisations are investing heavily in both on- and off-the-job training, employees’ perceived value of such differs markedly according to age and position. The research has important implications for China's HRD strategy in suggesting links between training and other human resource management (HRM) functions are yet to be evidenced.
\end{abstract}

Key Words: China, technical workers, training, development, age, position

\section{Introduction}

The economy of the People’s Republic of China (PRC) (hereafter referred to as China) has grown dramatically since the introduction of the open-door policy of the late 1970s and economic reforms of the 1980s and 1990s. Despite being the world's most populous country, with tens of millions of employees available as surplus labour, the rapid shift from agrarian economy through manufacturing to development of high technology industries has resulted in a critical shortage of trained technicians, dubbed the 'grey-collar' workers (GCW). The term 
'grey-collar' worker has been commonly used in Western nations and organisations to describe a 'greying' or aging population within the workforce. For the purposes of this paper it is used as defined in China as referring to the balance of persons whose occupation is not classified as white or blue collar, or as Wright (2007) describes them, "skilled technicians, employees whose job descriptions combine some white and some blue-collar duties” (Wright 2007). The term 'grey-collar' may refer to jobs that are taken by those who have university degrees but that may be below the employees' skill level, such as in retail where individuals have taken such employment, "mainly because they cannot find better-paying jobs" (Hennessy-Fiske 2006). Throughout this paper we use terms such as high tech technicians, highly skilled workers, trained technicians, skilled labour, knowledge workers, semi-skilled and skilled employees and unless we state otherwise that we are referring to white colour or blue colour workers, we are discussing grey-collar workers. While we acknowledge that such terms might suggest the type of work performed by white collar workers, we do reiterate that, in some cases, the work being performed by these technical workers is indeed akin to white collar work but that is being undertaken by people categorized as GCW because that is the only work available to them. Importantly, the impact of the shortfall of skilled GCW in China (and indeed a lack of work available for more highly skilled employees) has provided concern for government, organisations, training institutions, as well as scholars.

Since 2003, a number of reports have surfaced in the Chinese media indicating a severe shortage of GCW, particularly in the Eastern coastal industrial regions such as Shanghai (China Daily 2003, 2004; Zhao 2003; Xinhuanet 2004). While other Asian nations have reported similar significant and growing shortages of technically skilled workers (Hawley and Pack 2005; Venter 2003), the problem is more marked in China. In 2004, Shanghai alone was short of 15,000 GCW (Zheng and Liu 2004) which is said to increase to 
500,000 in the next five years (Sohu.com 2006) and it has been estimated that about $80 \%$ enterprises in China have a shortage of GCW, according to a report from a seminar on the employment and development of high-tech talents in 2004 (Zhongxiao Qiye AnShanWang 2004). A vice minister of the Ministry of Labour and Social Security (MOLSS), Mr. Zhang Xiaojian, has said that the problem has become a major bottleneck for China's economic development (People’s Daily Online 2004) and there are severe shortages of high-tech technicians, especially in traditional industries such as manufacturing and processing, and advanced and new technology industries such as electronic information, aviation and astronautics, as well as the modern service industry (MOLSS 2006). While the percentage of highly skilled workers or GCW is normally $20 \%$ to $40 \%$ in developed nations, in China it is less than $4 \%$, resulting in organisational demand that cannot be met from current labour supply. According to the survey results of Shanghai Labour and Social Security Bureau, every highly skilled worker could have 7.33 positions from which to select. In Shanghai, GCW are usually paid RMB3-6,000 (yuan) per month, while the most highly skilled ones can be paid RMB10-20,000 monthly. The problem of the great shortage of skilled labour force or GCW has reflected problems in China's occupational or technical-further-type education, but also reflected a lack of training at enterprise levels (Wen 2006) and is an important consideration in China’s future economic sustainability and development.

The emergence of a shortage of GCW in China has sparked reflection about the implications of the problem for government policy and organisational practice. The problem partly results from failures of China's higher education policy to develop more vocational training during the transition to a market economy emphasising development of knowledge workers rather than graduates from 'ivory towers' who only want to be white collar employees. Addressing the issue requires concerted efforts by state and provincial 
governments to implement educational and vocational training reform. Further, there is a need to provide support to organisations to develop HRD strategies and practices which assist with the comprehensive development of skilled workers. Yet, while the shortage of GCW has been acknowledged as a policy and organisational problem in China, thus far there has been no extant research investigating what organisations are doing to redress the skills shortage. This paper reports findings from a survey of semi-skilled and skilled employees in the Beijing region of the PRC. The present study does not explore government policy per se but rather focuses from an employee perspective on initiatives of organisations to capacity build skilled workers. The central research questions addressed in this paper are:

- RQ1: What training and development practices have been implemented in organisations to develop GCW skills?

- RQ2: How effective are training and development practices as perceived by employees?

- RQ3: Are there differences in perceptions of training effectiveness by age, gender and position of worker?

The paper begins with a brief statement of the theoretical underpinnings of the research. This is followed by review of the situation of GCW in China and exploration of what the central government has done to address the problems of the skills shortage. The research method and results of a survey conducted with 310 semi-skilled and skilled employees in Beijing, is then presented and a discussion is provided which considers the extent to which government policy has been implemented in the selected organisations. Finally, a conclusion is provided which details implications for theory and practice and issues for future research. 


\section{Theoretical underpinnings of the research}

We take as our theoretical underpinning the assumption that strategic human resource management (HRM) ensures motivation and enhanced performance of employees which in turn leads to enhanced organisational performance (Huselid, Jackson and Schuler 1997; Wright, Gardiner and Moynihan 2003; Wright, Gardner, Moynihan and Allen 2005). While early research on strategic HRM advocated the development of lists of best practices (Pfeffer 1994), we take as our premise the belief in bundling of high performance work practices (see Stavrou and Brewster 2005) or having a system approach to HRM (see Bowen and Ostroff 2004) as most effective in ensuring organisational performance. Importantly, it has been noted that training is a key element of the bundles of practices arising from research into high performance work systems (Ashton and Sung, 2002, cited in Smith and Smith 2007). As one of the key HRM functions we argue that training and development is most effective in motivating and retaining high quality human resources within organisations when operationalised in concert with a bundle of other high performance work practices to which it is interrelated, namely rewards and performance management. Our assessment of the effectiveness of training provided by the researched cohort of organisations to increase skill levels of GCW is also based on a belief in the necessity of organisations' ensuring that training is integrated with education and career development beyond the immediacy of the current position or organisation to ensure increased individual as well as organisational competencies and a ‘learning organisation’ (see Hartel, Strybosch and Blyth 2006).

\section{Grey collar workers in China}

In the following sections we provide an overview of how GCW have been defined in China, why a shortage of GCW has developed and what has been the PRC government's response to the issue. The purpose of providing such information is to detail the HRD problem in respect 
to GCW so as to provide a research foundation from which to explore whether the studied cohort of organisations have implemented government suggested training and development and perception by workers of its effectiveness.

In China, the term grey-collar is often used in association with the application of high technology in new industries, such as information technology and telecommunication, or emerging professions that utilise the latest technology such as advertisement design, electronic engineering technology, website management, conference and exhibition organisation, fashion design, software developer, packaging design (Li 2006). The first GreyCollar Occupation Competition was held in Shanghai in 2003 and listed 25 'grey-collar' occupations, most of which were emerging high-tech occupations including animation design, game manufacturers, information protection and shield, advertisement design, and movement capture technology (ZhongGuo XinWen Wang [Chinanews.cn] 2004), though it should be noted that Shanghai even includes astronauts, airplane pilots, surgical doctors and journalists in the category of 'grey-collars' (Sounthcn.com,2007) which we define as white-collar workers.

Professor Li Jingyuan, a Chinese scholar is believed to be the first person to have conducted systematic research on China's GCW. He defines them as those who have technical skills operating on the frontline and as on-site managerial staff. Li (2006) defines GCW as having the following characteristics: theoretical training and practical experience; professional knowledge and practical skills; good at using hand and intellectual skills; and capable of both maintaining hardware equipments, and developing and applying operating software. Then, the Ministry of Labour and Social Security (MOLSS) did not specifically utilise the terminology 'grey-collar', but instead used high-tech technicians or more broad 
terms such as technicians (People’s Daily Online 2004). In its standard national occupation classification 2006, MOLSS identified 113 occupations which cover both traditional technicians and emerging jobs in association with new technology (MOLSS 2007b). Hence, the term 'grey-collar' worker is synonymous with 'technicians' in China, and in this sense it is exchangeable with technicians in this paper. Though other research has suggested that China has an excess of unskilled workers but also a shortage of professionals and managers (Ke et al,2006), the focus of this paper is on the GCW; a critical human resource for organisational competitiveness in the knowledge economy era. The following section addresses why a shortage of GCW has emerged.

\section{Why is there a shortage of GCW in China?}

To some extent some of the problems of China's current shortage of skilled workers can be traced to historical events such as the cessation of all formal education and loss of linkages between industry and vocational education during The Great Cultural Revolution (1966-76) (Donaldson 2006). Despite expansion in education through economic reconstruction and the 'open door policy” commenced in the late 1970s, China is still beset by the legacy of the onechild policy which has left it with an aging population and demand upon workers to provide for these financial liabilities. Further, the emphasis on learning leading to officials' positions (which can be traced partly to Confucian ideology - xue er you ze zhi) has advocated that those who do not perform manual labour should go to university and become professional white-collar employees (Li 2006). Consequently people attach great importance to academic education rather than vocational education (Misko 2006) and this social norm has prevented many university graduates from becoming 'grey-collars' by avoiding working at the frontline (Li 2006). 
The situation has been further compounded by increased demand for GCW. There has been a large increase in the demand for high-tech technicians due to China's rapid economic development, industrial restructuring and upgrading, and the emergence of new industries (People’s Daily Online 2004; Chen 2004; MOLSS-Occupational Skill Evaluating Centre 2006). China's labour-force problems are related to a soaring demand for high-level human resources with a simultaneous abundance of low overall labour force quality (Ke et al. 2006: 35) - a situation which is exacerbated by the movement of skilled workers to other countries. Moreover, Li (2006) attributes the shortage of 'grey-collar' workers with the distortion and dysfunction of HRM and development in China. This has inevitably pointed to a failure of public policy in higher education, particularly the development of vocational training. The following section provides an overview of what the PRC government has done to attempt to address the shortage of GCW.

\section{China's response to the shortage of GCW}

Associated with the abovementioned issues are specific HRD issues, notably that there has historically been: a lack of national control of public policies on training and development; low investment in training and development; and a low quantity of teaching personnel compared with demands (Xie and Wu 2001; Zhu 2005). Yet, the central government has made clear its intention to redress these problems through emulating vocational training utilised in various Western nations and a commitment to emphasising the importance of organisational training and development.

Following Deng Xiaoping's 1978 commitment to the principle of combining education with industrial production and labour, China has worked actively towards establishing vocational education as a priority with the 1990 establishment of the Central 
Institute for Vocational and Technical Education (Ministry of Education). The period 1996 to 2004 represented intensive reform and a greater increase in linkages with industry with the impetus for reform based on the passing of the Vocational Education Law in 1996 (Misko et al. 2005).

It is difficult to make country comparisons between China and Germany, Australia or the UK, in terms of vocational education (VE) because of major differences in individual country traditions, the size of political, economic and educational structures and institutions (Misko et al. 2005). Nonetheless, China has been investigating how it can further improve its VE by looking at how other countries have gone about modifying their VE systems to meet the demands on a changing world economy and assessing the value of utilizing some of those practices (Misko et al. 2005). In so doing China introduced the German dual system of apprenticeship training in some Chinese schools on a trial basis in 1984 (Misko et. al, 2005). Moreover, in 2006, the German-Chinese Electric Mechanical Technology Limited Company (Henan) and the German Chamber of Commerce and Industry (GCCI) signed an agreement to build a training centre in the provincial capital of Zhengzhou. It was reported that the centre used Germany’s dual system in vocational training (BBC Monitoring Asia Pacific 2006). Other models of VE-industry collaboration are briefly summarised by Misko and others (2005: 39-41) as follows: First, there is a 'training by order' model - in which "the school chooses its enterprise partner, and signs an agreement to provide human resource training”. Second, there is a 'zero period of adaptation' model in which "the VE school identifies the knowledge and skills requirements of the enterprise, and then makes full use of enterprise resources to provide an appropriate training program to produce graduates for industry who can move directly into positions without any other specific orientation requirements”. Third, there is a model referred to as the 'combined school-factory' model which ensures that "the 
VE school uses its specific expertise and resources to run a combined school-factory enterprise which meets the needs of the local economy". Finally, the 'international cooperation' model advocates that "the school aims to improve the quality of its teaching, and provision of services to the local economy by reflecting on and utilising the VE experience of overseas countries to improve its own operation, and establishing networks for international cooperation and exchange”.

\section{MOLSS and the eleventh five-year plan}

Importantly, the MOLSS has attempted to address the ongoing shortage of GCW by advocating enhanced training as detailed in its Eleventh Five-Year Plan (2006-2010). The Chinese government including MOLSS had been initially reluctant to recognise that the problem of the shortage of 'grey-collar' workers was primarily related to a failure of government policy on technical training to keep pace with economic development. However, the State Council and MOLSS have issued several policy papers stressing the need for vocational training, with five key measures identified. First, a system of occupational qualification certification was established to open a new channel for national HRD by emphasising occupational qualifications as equally important as university and higher degrees. Second, state policy elevated the social status and increased economic benefits for high-tech technicians. Third, there has been government reliance on universities and colleges for training of skilled technicians. Fourth, there has been a reliance on key enterprises for the training of highly-skilled and high-tech technicians. Fifth, government need for developing a national plan for the development of high-tech technicians has been identified (Chen 2004). MOLSS has five specific programs and one action plan that are to be implemented in the period of the state Eleventh Five-Year Plan, namely, "the new technician training and promoting program”, “the program for re-employment skills of unemployed and laid-off 
workers", "the ability leading to entrepreneurship program", "the program for the employment with skills for the rural labour force”, "the state technical qualification navigating program", and "the action plan for connecting skills with positions" (MOLSS 2007a).

In 2003, the Chinese Communist Party (CCP) held an important meeting on national HRD policy and adopted the strategy of facilitating national development through strengthening HRD (Xinhua Net 2003). The decision made at this meeting formulates the guidelines for national HRD, which were enacted in a policy paper titled 'Decision on Further Strengthening the Work for Talent Development'. By “talent” they meant: party-government cadres, business managers, and professional and technical personnel. The meeting emphasised capacity building as the core for HRD and proposed the shifting of focus from education qualification and experience to competence and performance in relation to recruitment and assessment of talent (The CCP Central Committee and the State Council 2003).

Based on this strategy, the State Council and MOLSS have subsequently issued several policy papers with further measures for facilitating the training and development of technicians and skilled workers. This includes the recent MOLSS “Guidelines for establishing the system of high skilled talent development for the Eleventh Five-Year Plan (2006-2010)” (MOLSS [No.10] 2007a). According to the guidelines, the strategy of strengthening national development through talent development will be implemented by accelerating skill training and capacity building, improving evaluation systems and enhancing reward mechanisms. The overriding goal is to increase the number of skilled employees who are high-skilled to more than $25 \%$ of total skilled workers and, among them, $5 \%$ are to be qualified technicians and senior technicians by the end of the eleventh five-year plan. While national and provincial 
government will guide and govern talent development through promoting the systems of talent evaluation and reward, improving the services for security and mobility of talent, and increasing input in vocational education and training, organisations are being urged to establish and improve a modern enterprise training system (MOLSS 2007a). The following details the requirements for enterprises in relation to staff training, evaluation of high skilled workers and reward system.

In respect to enterprise staff training, the effectiveness of technical training of state enterprises will be incorporated into objective management and used for managerial performance assessment. Non-state enterprises are also encouraged, supported and guided to undertake technical training. Concrete measures include (MOLSS [No.10] 2007a):

- developing a high-tech talent team through on-the-job training with knowledge and skills in relation to new technology, new equipment, new materials,

- establishing systems of trainer, apprenticeship and continuing study programs for technicians,

- supporting and encouraging enterprises to develop the talent they need through overseas training and study.

In regard to assessment and corresponding to the national system of occupational qualification certification and the talent assessment policy which is competence oriented, performance and contribution focused, enterprises are expected to broaden channels for the development of high-tech talent. Restraints in relation to age, experience, position and proportion will be eliminated; practical methods for technical assessment in the production process will be extended; and the combined use of on-site assessment and performance appraisal will be promoted for technician evaluation (State Council [No.35] 2005). 
Enterprises are urged to improve their reward mechanisms to take into account training, performance, appointment and compensation simultaneously, providing preferred rewards for high skilled workers, especially those of excellent talent, in accordance with market demand and enterprise performance. Occupational qualifications are to be used for appointment and promotion; remuneration is to be based on performance and contribution; and the enterprise wage system will be linked to the promotion of occupational qualification certification system (State Council [No.35] 2005). Moreover, it has becomea requirement that $1.5 \%$ of payrolls should be allowed for education and training for ordinary enterprises, while $2.5 \%$ would be required for high performing enterprises which demand high skilled employees and have a heavy burden for staff training (State Council [No.35] 2005). Prior to examining whether our studied cohort of organisations have implemented training and development practices consistent with recommendations of MOLSS and the Eleventh FiveYear Plan, we outline the methods employed for this study.

\section{Method}

The research on which this paper is based involved analysis of data collected through a survey of semi-skilled and skilled employees in the Beijing area of China. While the dramatic socioeconomic differences throughout China are recognised, a decision was made to undertake research only in one region for consistency of data as well as in recognition of the expected implementation of recommended government initiatives in vocational education and training in organisations in the Beijing area given their location within the central government district. The present research was undertaken collaboratively between academics with research expertise in organisations in China, who are based at a leading Australian university and researchers at the China Academy of Labour and Social Security (CALSS). 


\section{Sample and procedure}

Four organisations were selected by the researcher at CALSS on the basis of pre-existing research relationships. Such insider status (see Siu 1996) was critical to achieving agreement to undertake research in organisations in China. The four organisations, located in Beijing, were drawn from a multi-industry background of organisations within the public (stateowned) and private (or mixed) sector. The selection of organizations through use of political or administrative contacts does suggest the potential for bias on the part of the CALSS researcher. However, it is a strategy that was also used by an international team of researchers whom reported on best practice in IHRM (Von Glinow, Drost and Teagarden 2002) and is a strategy regularly employed in China as a means of gaining potential access (see Hutchings 2004). However, while insider status was utilised to gain access to the organisations, the employees themselves were randomly selected within each of the four organisations (see below).

The questionnaire was not administered by mail as such surveys elicit very low response rates in China and respondents have a strong tendency for socially desirable responding due to fear that their manager will read the survey responses. Accordingly, the questionnaires were administered through focus groups. Within each organisation, 100 semi-skilled and skilled employees were randomly selected and divided into five focus groups of approximately 20 respondents. The CALSS researchers sat with the respondents while they completed the questionnaire and answered any questions that required clarification, while not influencing the choices that respondents made for each question. Such an approach is regularly utilised in China to address the difficulties of undertaking surveys utilising standard Western research 
methods (for further discussion, see Hutchings 2004; Roy, Walters and Luk 2001). All potential respondents were assured of confidentiality and the voluntary nature of participation.

The questionnaire items were adapted from an instrument validated in China by Zhu (2005) and based on an earlier survey by Von Glinow and Teagarden (1990). The survey instrument included basic demographic data about the respondents as well as close-ended questions about the type of training each employee had received and when it was provided, and their perceptions about the relationship between training and performance for skills development.

The questionnaire was initially written in English. The questionnaire was then translated into Mandarin by one of the bilingual researchers in Australia. The questionnaire was then back translated by another bilingual researcher in Australia to ensure accuracy and consistency in a cross-cultural context. It was necessary to back translate the entire questionnaire because, while the majority of questions had been pre-validated in the earlier survey conducted by Zhu (2005), our questionnaire included additional items developed for this study that were of specific reference to the focus on grey collar workers.

\section{Results}

A total of 310 semi-skilled and skilled employees completed the questionnaire. A summary of background information on the respondents is shown in Table 1. As shown in Table 1, the majority of respondents (62.1\%) were workers, the remainder supervisors or managers. The majority of respondents (82.6\%) was male and aged less than 40 years of age (82.9\%). As expected, the majority of employees (77.7\%) had some form of post-school qualification, but only $6.7 \%$ had a tertiary degree. We acknowledge a limitation in that the majority of the respondents being male may have biased the results in that there is a possibility that given historical gender work differences in China males may be better 
represented amongst higher level positions in organisations, may have long length of tenure in organisations, may receive more training than females and given family commitments of women may be more prepared to undertake training outside of work hours or off-the-job. However, the gender distribution is consistent with the male dominance in the industries of the examined case study organisations. About a third (32.9\%) of respondents had worked for more than 10 years in their organization.

Insert Table 1 here

\section{Timing of training}

Figure 1 presents the time when on-the-job training was reported by the respondents. As shown in Figure 1, close to half (45.0\%) of the employees reported that the training occurred in the first week of employment. However, just under a third (31.6\%) of respondents said that on-the-job training was continuously provided by their organisation. Only $3.6 \%$ or 11 respondents reported no access to on-the-job training.

Insert Figure 1 here

Table 2 shows that the majority (71.9\%) of the employees reported that they had received off-the-job training provided by their organisation during work time and another 39.7\% said they received off-the-job training provided by their organisation outside work time. Few reported receiving training outside the organisation which they have requested which was not an initiative of the organisation.

Insert Table 2 here 


\section{Participation in training and development programs}

Table 2 also shows that the majority of respondents (65.8\%) reported having attended an occupational skills training program. Of the employees, $57.4 \%$ reported attending an induction/orientation program and over a third (36.5\%) a technical/professional training program. However, only about a quarter of respondents reported attending organisational 'behavioural' or interpersonal skills training.

\section{Perceived effectiveness of training and development practices}

In general, respondents reported that organisational practices were moderately effective across a range of performance dimensions. Two areas of training effectiveness were, however, poorly endorsed. As shown in Table 3, over half (52.3\%) of the employees reported that training practices had not provided them with an increase in salary. In addition, over a third (36.2\%) of respondents reported that training practices had not provided them with an opportunity for promotion.

Insert Table 3 here

However, respondents’ reported that training and development practices had a positive impact on preparing them to be more effective in their work, increasing their technical abilities, interpersonal abilities, teamwork, job confidence and work motivation, with all mean scores at or above the midpoint (3) of the 5-point rating scale. As score of 3 on the 5-point scale relates to belief in a moderate effect of the training practices, it can be thus argued that a mean score close to 3 suggests that the typical response is one of a favourable attitude to the perceived value of the training practices. It should be noted that respondents were less certain that training and development practices had remedied any past performance problems, with the mean score (2.51) just under the midpoint of the scale. It is also important to note 
that none of the mean scores were rated very highly (e.g. above 4 on the rating scale), suggesting that levels of perceived training effectiveness were moderate in this sample.

Perceived effectiveness of training varied by age, gender and position of the respondent. Spearman's correlation ( $r s$ ) for ordinal data revealed that older employees were more likely than their younger peers to report that training had provided an increase in salary ( $r s=.27, p<.05)$, greater opportunities for promotion $(r s=.21, p<.05)$, and prepared them better for future job assignments $(r s=.22, p<.05)$. In addition, older employees were more likely to state that they had developed skills to do a number of jobs ( $r s=.23, p<.05$ ), improved their understanding of the business ( $r s=.19, p<.05$ ), and increased their confidence to undertake work tasks ( $r s=.16, p<.05)$. Older employees were less likely to say that training was provided when they first started in the organisation, ( $r s=-.25, p<.05$ ), motivates them to continue to work in this organisation ( $r s=-.13, p<.05$ ), and builds teamwork in the organisation $(r s=-.12, p<.05)$.

By contrast, there were only two statistically significant relationships between gender and perceptions of training effectiveness. Females were less likely than males to report that training practices had increased their technical abilities $(r s=-.13, p<.05)$ and that training had prepared them better for future job assignments ( $r s=-.12, p<.05)$. In interpreting these results it is important to note correlations close to .10 in magnitude are relatively weak by Cohen’s (1992) standards for effect size.

Compared with managers/supervisors, workers were less likely to report that training had provided greater opportunities for promotion $(r s=-.30, p<.05)$ and an increase in salary ( $r s=-.28, p<.05$ ). Workers were also likely to believe that training had increased their 
technical abilities ( $r s=-.29, p<.05$ ), and improved their understanding of the business ( $r s=$ $.20, p<.05)$. Although the effects were not as strong, workers were also less likely than managers to say that training had prepared them better for future job assignments $(r s=-.17, p$ $<.05$ ), developed skills to do a number of jobs ( $r s=-.18, p<.05$ ), increased confidence to undertake work tasks ( $r s=-.16, p<.05$ ), and taught them about the organisation's values ( $r s$ $=-.12, p<.05)$. Finally, workers were also less likely than managers to believe that training practices are better implemented than in other organisations in which they had been employed $(r s=-.19, p<.05)$. However, workers were more likely than managers to report that training practices were provided when they first started in the organisation $(r s=.15, p<.05)$.

\section{Discussion}

Our findings are consistent with recommendations by MOLSS that GCW should receive extensive on-the-job training to enhance their technical skills. Close to half of our respondents reported that the training they received occurred in the first week of employment and almost a third maintained that on-the-job training was continuously provided by their organisations. Yet, there is limited indication of MOLSS recommendations that organisations should also invest in development of employees' skills through further study conducted outside the workplace. While well over $50 \%$ of respondents indicated that they have TAFE or technical qualifications and a high percentage of employees have worked for their current organisation for over 10 years, there is little evidence that their current employer provided them with time and resources to undertake this further study. Though a majority of respondents reported that they had received off-the-job training provided by their organisation during work time, very few indicated that they had received organisational support for study and most of the off-thejob training was in the form of occupational skills training programs and did not involve 'behavioural' or interpersonal skills training which might assist with career development. This 
finding has supported earlier evidence of a lack of behavioural training in China's industrial enterprises (e.g. Von Glinow and Teagarden 1990; Zhu 2005). A further aspect of MOLSS recommendations, namely, overseas training, was also not indicated in this study. It could be argued, however, that the organisations which we studied may not be expected to participate in overseas training, though, as there is a tendency for this to be offered either to employees working in multinational corporations or to senior government officials who receive executive public management training courses offshore (Anon 2006).

Training effectiveness was not strongly indicated in this study with cases of positive impact reported in improved personal and team work practices, technical abilities, and work motivation, the latter being surprising given that a large percentage of respondents suggested that training practices had not provided them with an increase in salary or promotion. This contraindicates earlier research on China's HRM practices suggesting that, in the post-Iron Rice Bowl economy of industrialised China, there is a growing link between worker skills, motivation and external rewards (Cooke 2005).

Our research suggests a few gender differences, namely that females were less likely than males to report that training practices had increased their technical abilities and that training had prepared them better for future job assignments; a finding which conflicts with earlier research indicating that increased levels of training in China have been linked to higher levels of job performance (Zhu and Dowling 2000). However, the magnitude of these gender differences were relatively small and given that almost $83 \%$ of respondents were male, the findings must be interpreted with caution. 
More importantly older employees were more likely to report that training had provided: an increase in salary, greater opportunities for promotion, prepared them better for future job assignments, developed skills to do a number of jobs, improved their understanding of the business, and increased their confidence to undertake work tasks. However, the research findings indicate that older employees were less likely to be motivated to continue their work in the organisation compared with their younger peers. This correlation is somewhat surprising , but it might due to a situation in which when employees age either they could move to other organisations with better pay and rewards for their rich experience and skills or simply consider retirement. As only 17.1 per cent of the respondents are in the age group over 40, though, this finding should not be over generalised.

Further, compared with managers/supervisors, workers were less likely to report that training had provided greater opportunities for promotion, an increase in salary, increased their technical abilities, improved their understanding of the business, prepared them better for future job assignments, developed skills to do a number of jobs, increased confidence to undertake work tasks, and taught them about the organisation's values. Workers were also less likely to believe that training practices are better implemented than in other organisations in which they had been employed, but more likely than mangers to report that training practices were provided when they first started in the organisation. Note also that many workers were also younger than their managerial peers. While it is to be expected that managers would report that training had led to promotion and increased salary because their higher level positions provide evidence that they have received rewards from the organisation which they may choose to attribute to training and development programs, among other activities which may result in more pay or promotion, the finding that older workers are more likely than younger workers to report that training can lead to increased salary and promotion 
is curious. Earlier research on China's HRM practices has indicated that in all but state-owned enterprises (SOEs) there has been a shift from the Communist era in which promotion was based on seniority and/or political connections in favour of remuneration and promotion being based on skills, qualifications and experience for higher level positions (Michailova and Hutchings 2006). Our research suggests that in some organisations there may still be a relationship between seniority and pay and promotion in that older workers are more convinced of the value of training for future prospects within the organisation. Further, research on younger employees internationally and in China suggests that they are more likely than older employees to value training and see it as contributing to their own employment potential and boundaryless careers. Our research contradicts this in indicating that older workers place greater value on training and development than do younger workers.

\section{Conclusions, implications and issues for future research}

This research has some important implications for theory about HRD and HRM in China in suggesting that in this cohort of organisations there is no indication of a definitive link between training and development practices and other HRM functions such as remuneration and promotion, performance assessment and broader career development. To this end, the findings of our research contradict a body of current research on HRM in China which has proffered that rewards and incentives, rather than seniority (tenure of employment) and political connections are increasingly linked to promotion (Farley, Hoenig and Yang 2004; Zhu and Warner 2005). Further, our research shows little evidence of their being systematically thought out strategic approaches to HRM practice and policy within the studied organisations with the majority of the training being in the form of induction rather than career development and further education. It should be noted, though, that our research involved SOEs and collective enterprises (COEs) in China's political capital and it might be 
expected that the findings could be different in private organisations and certainly in foreigninvested enterprises. Extant research on HRM in China suggests that the evolutionary nature of this transitional economy's HRM is that it has moved beyond a focus on training and development only to linking HRD strategies to other aspects of HRM functionality and strategy as well as evidencing that Chinese organisations are becoming more strategic in their thinking and moving beyond a purely personnel management role. Yet, earlier research on HRM in China has also suggested that there are distinct differences between the HRM practices of Chinese enterprises across the varying sectors with foreign-invested enterprises being much more likely to adopt Westernised strategic HRM approaches or a hybrid of Western and traditional practices, while SOEs and COEs are more likely to follow practices utilised during earlier years of Communist rule (for further discussion see Zhu 2005).

Our research adds value in being one of the first studies to examine GCW and to provide understanding of the attitudes of this group of workers towards training and development. However, what is more significant is that these initial findings add to the literature on HRM in China generally in suggesting that there is a continuing propensity for SOEs to maintain historical employee relations practices - which has implications for such organisations' potential ability to provide HRD practices, policies and strategy which can advance their grey collar employees' skills as well as their in-house career development and likelihood for boundaryless careers.

We recommend future research explore a wider range of training and development issues for GCW in a more diverse range of organisations and across all types of enterprises. Moerover, given that the study was conducted in the political capital of Beijing, it might be expected that developmental practices would differ from the business capital of Shanghai and 
export-dominated region on the Eastern seaboard as well as from lesser developed cities and towns in the interior and Western and Northern provinces. Thus, there is also value in broadening future research to a larger geographical scope of China. Moreover, while there were few statistically significant differences between male and female perceptions of the value of training, that this research found that females reported less of a relationship between training and on-going work performance is interesting and also warrants further investigation. As noted the sample organisations are male-dominated and there is a predominance of males amongst GCW, but future research might be able to provide greater insights into why there seems to be differing attitudes to the value of training between males and females.

Given the relatively small number of organizations studied it may not be possible to generalize the results, we do caution that our findings are tentative and that our suggestions might be used only if deemed of relevance to particular organisations or consistent with existing government initiatives. Our research has potential relevance for China's developmental strategy to increase skills levels of GCW and address the shortage of employees equipped to undertake grey-collar employment in that the findings suggest that for the sampled cohort of organisations there is evidence of being largely focused on induction training and on-going on-the-job or off-the-job training which is largely task- or technical skills-oriented. It would be beneficial for organisations which have such an approach to invest in employees' broader career development by providing support for further study, secondments or extension training to develop managerial skills and interpersonal competencies as well as technical skills. Organisations might also consider developing an overarching HRM strategy which links the range of HRM functions to ensure that HRD is knowledge-focused and implemented to build organisational commitment and ensure retention of younger GCW who receive training not just to ensure functional competencies 
but also for ongoing career development, motivation and interpersonal effectiveness; which can lead to managerial opportunities.

\section{References}

Anon.2006. Making the global grade: Chinese managers are the latest enrollees in western executive education $\quad$ classes. Knowledge Wharton. http://knowledge.wharton.upenn.edu/article.cfm?articleid=1597. $\quad$ (retrieved 15 September 2008).

Bowen, D.E and C. Ostroff 2004. Understanding HRM - firm performance linkages: the role of the "strength” of the HRM system. Academy of Management Review 29, no. 2: 203221.

Chen, Y. 2004. The role of grey-collars in the labour market. Shanghai Zhiye Peixun Zhidao Fuwu Wang, http://www.12333.gov.cn. (retrieved 24 January 2007).

China Daily. 2003. Gray-collar group debuts. China Daily. 19 November. http://www.chinadaily.com.cn. (retrieved: 18 January 2007).

China Daily. 2004. China badly needs Gray-collars for manufacturing. China Daily, 21 March, http://www.chinadaily.com.cn. (retrieved: 18 January 2007).

Cohen, J. 1992. A power primer. Psychological Bulletin 112: 155-159.

Donaldson, C. 2006. China treat looms in skills shortage. Human Resources Magazine 6: February.

Cooke, Fan-Lee. 2005. HRM, work and employment in China. London: Routledge.

Farley, J.U., S. Hoenig and J.Z. Yang 2004. Key factors influencing HRM practices of overseas subsidiaries in China's transition economy. International Journal of Human Resource Management 15, no. 4/5: 688-704. 
Hartel, C.E.J., V.E. Strybosch and A.L. Blyth 2006. The learning organisation. In Contemporary issues in Human Resource Development: An Australian Perspective, ed. P. Holland and H. de Cieri, 289-304, Frenchs Forest: Pearson.

Hawley, J. D., and J. Paek. 2005. Developing human resources for the technical workforce: A comparative study of Korea and Thailand. International Journal of Training \& Development 9, no. 1: 79-94.

Hennessy-Fiske, M. 2006. That raise might take 4 years to earn as well: Those with bachelor's degrees are finding their incomes stagnate despite a growing economy, Los Angeles Times, 24 July. www.latimes.com (retrieved: 18 January 2007).

Huselid, M.A., S. E. Jackson and R.S. Schuler 1997. Technical and strategic human resource management effectiveness as determinants of firm performance. Academy of Management Journal 39: 949-969.

Hutchings, K. 2004. Behind the bamboo curtain: problems and pitfalls in doing research with expatriates in China. In Fieldwork in Transforming Societies: Understanding Methodology from Experience, ed. S. Michailova, and E. Clark,.136-157. London: Palgrave.

Ke, J., T. J.Chermack, Y.Lee and J. Lin. 2006. National HRD in transitioning societies in the developing world: The People's Republic of China. Advances in Developing Human Resources 8, no.1: 28-45. 
Li, J. Y. 2006. Chinese gray-collars: Strata of highly skilled operatives and on-site managing staff in the era of knowledge economy. In Chinese: ZhongGuo HuiLing: ZhiShi JingJi ShiDai de GaoJi JiNeng CaoZuo yu XianChang Guanli JieCeng. Beijing: China Economic Publishing House.

Michailova, S. and K. Hutchings. 2006. National cultural influences on knowledge sharing in China and Russia. Journal of Management Studies 43, no,3: 383-405.

Ministry of Labour and Social Security (MOLSS)-Occupational Skill Evaluating Centre. 2006. Mr Zhang Bin, Deputy Director-General, MOLSS: The Shortage of High-tech Talents Constrains Industrial Upgrading. 18 December. www.molss.gov.cn (retrieved: 25 January 2007).

Ministry of Labour and Social Security (MOLSS). 2007a. Guidelines for establishing the system of high skilled talent development for the eleventh five-year plan (2006-2010). Beijing: MOLSS.

Ministry of Labour and Social Security (MOLSS). 2007b. Standard national category of 113 occupations issued by MOLSS in 2006. Beijing: MOLSS.

Misko, J., L. Yufeng., J. Dayuan, W. Quanquan, and W. Zerong. 2005. Linking vocational education and training with industry in Australia and China. National Centre for Vocational Education Research. Adelaide: NCVER.

Misko, Josie. 2006. Vocational Education and training in Australia, the United Kingdom and Germany. National Centre for Vocational Education Research. Adelaide: NCVER.

People’s Daily Online. 2004. China strives to cultivate grey collar workers. 21 December, http://english.peopledaily.com.cn (retrieved: 18 January 2007).

Pfeffer, J 1994. Competitive Advantage through People. Boston, MA: Harvard Business School Press. 
Roy, A., P. Walters and S. Luk, 2001.Chinese puzzles and paradoxes conducting business research in China. Journal of Business Research 52: 203-210.

Schmidt, K and P.N. Foster. 1997. Germany's dual vocational training system. Tech Directions 57, no.3: 15-18.

Sekaran, Uma. 2000. Research Methods for Business. $3^{\text {rd }}$ edn. New York: John Wiley.

Siu, Yee-Man. 1996. Getting in, getting on, getting out: The role of participant observation research in a professional organisation. BRC Working Paper Series Number 960202, Hong Kong: Hong Kong Baptist University.

Smith, A. and E. Smith 2007. The role of training in the development of human resource management in Australian organisations. Human Resource Development International, 10, no.3: 263-279.

Sohu.com. 2006. There will be a shortage of "grey-collar" workers in next five years in the municipality. 8 March. http://news.sohu.com. (retrieved 20 February 2007).

Southcn.com. 2007. Shanghai classifies 25 occupations including pilots and surgical doctors as grey-collars www.southcn.com (retrieved 21 February. 2007).

Stavrou, E.T. and C. Brewster, C. 2005. The configurational approach to linking strategic human resource management bundles with business performance: myth or reality?', Management Revue 16, no. 2: 186-201.

The CCP Central Committee and the State Council. 2003. Decision on further strengthening the work for talent development. 26 December. www.most.gov.cn (retrieved 1 June 2007) Beijing: CCC Central Committee and State Council.

The State Council [No. 35]. 2005. Decision for enhancing the development of vocational education. Beijing: State Council. 
Venter, K. 2003 Building on formal education: employers’ approaches to the training and development of new recruits in the People's Republic of China. International Journal of Training \& Development 7, no.3: 186-202.

Von Glinow, M. A., and M.B. Teagarden. 1990. Contextual determinants of human resource management effectiveness in international cooperative alliances: Evidence from the People’s Republic of China'. In International Human Resource Management Review, ed. A. Nedd, Volume 1, 75-94, Singapore: McGraw-Hill Book Co.

Von Glinow, M.A., E.A. Drost and M.B. Teagarden. 2002. Converging on IHRM best practices: lessons learned from a globally distributed consortium on theory and practice. Asia Pacific Journal of Human Resources 40, no.1: 146-66.

Wen, Z. 2006. China Needs “Blue Collar” Skilled Workers Urgently. People's Daily Overseas Edition, 3 November: 4.

Wright, L.S. 2007. Deciphering Office Lingo. Executive Coaching Studio, www.executivecoachingstudio.com (retrieved: 18 January 2007).

Wright, P.M., T.M. Gardner and L.M. Moynihan 2003. The impact of HR practices on the performance of business units. Human Resource Management Journal 13, no.3: 2136.

Wright, P.M., T.M. Gardner, L. Moynihan and M.Allen 2005. The Relationship Between HR Practices and Firm Performance: Examining Causal Order, Personnel Psychology 58: $409-446$

Xinhuanet 2003. Hu Jintao on the implementation of the national development strategy through talent development and the insistence of the principal that the party regulate the talent. www.xinhuanet.com. (retrieved: 22 December 2007). 
Xinhuanet 2004. Zheng Huiqiang, a Member of the National People's Congress: 'China Made' is Faced with a Fault of 'Gray-collars'. Translated from the Chinese RenDa DaiBiao Zheng HuiQiang: 'ZhongGuo ZhiZhao' MianLin 'HuiLing' DuanCeng. www.xinhuanet.com, (retrieved: 24 January 2007).

Xie, J., and G. Wu. 2001. International briefing 10 - training and development in the People's Republic of China. International Journal of Human Resource Management 5, no.3: 223-32.

Yin, Robert. 2003. Case Study Research: Design and Methods. Thousands Oaks, CA: Sage Publications.

Zhao, C. 2003. Call for “Gray-collars”. Guangming Daily, 25 ${ }^{\text {th }}$ December. www.cas.ac.cn (retrieved: 24 January 2007).

Zheng, H. and Z. Liu. 2004. Economists say China has shortage of “Grey-collar” workers. BBC Monitoring Asia Pacific 21 March: 1.

ZhongGuo Xinwen Wang [Chinanews.cn]. 2004. What is gray-collar class? Translated in Chinese: HuiLing JieCeng shi ShenMe? 12 February. www.nppn.com.cn (retrieved: 24 January 2007).

ZhongGuo Yahoo. 2006. How are white-collar, gold-collar and gray-collar defined? what are the differences? Translated from the Chinese: BaiLing, JinLing, HuiLing shi ZenMe DingYi de? You ShenMe QuBie? 12 December. http://ks.cn.yahoo.com (retrieved 24 January 2007).

ZhongXiao QiYe AnShan Wang (2004) 80\% Enterprises Lack 'Gray-collars'. 24 June, www.assme.com.cn (retrieved: 24 January 2007).

Zhu, Cherrie. Jiuhua. 2005. Human resource management in china: past, current and future hr practices in the industrial sector. London and New York: RoutledgeCurzon. 
Zhu, C. J and P. J. Dowling, 2000. Managing human resources in state-owned enterprises in transitional economies: A case study in the People's Republic of China. Research and Practice in Human Resource Management 8, no.1: 63-92.

Zhu, Y. and M. Warner 2005. Changing Chinese employment relations since WTO accession. Personnel Review 34, no.3: 354-369. 


\section{Table 1: Sample Characteristics (\%)}

\begin{tabular}{|c|c|c|}
\hline \multirow[t]{4}{*}{ Age (in years) } & $<30$ & 54.2 \\
\hline & $30-39$ & 28.7 \\
\hline & $40-49$ & 14.8 \\
\hline & $50-69$ & 2.3 \\
\hline \multirow[t]{2}{*}{ Gender } & Male & 82.6 \\
\hline & Female & 17.4 \\
\hline \multirow[t]{5}{*}{ Highest educational } & High school or less & 22.3 \\
\hline & Some college education & 16.1 \\
\hline & Technical school & 29.4 \\
\hline & TAFE & 25.5 \\
\hline & Tertiary level education & 6.7 \\
\hline \multirow[t]{4}{*}{ Position } & Worker & 62.1 \\
\hline & Supervisor & 24.6 \\
\hline & Line manager & 7.8 \\
\hline & Middle level manager & 5.5 \\
\hline \multirow[t]{7}{*}{ Years in current job } & $<1$ & 7.1 \\
\hline & $1-2$ & 16.1 \\
\hline & $3-4$ & 17.7 \\
\hline & $5-6$ & 17.4 \\
\hline & 7-8 & 9.7 \\
\hline & $9-10$ & 5.8 \\
\hline & More than 10 & 26.1 \\
\hline \multirow[t]{7}{*}{ Years in organisation } & $<1$ & 7.7 \\
\hline & $1-2$ & 14.8 \\
\hline & $3-4$ & 16.8 \\
\hline & $5-6$ & 11.9 \\
\hline & $7-8$ & 10.0 \\
\hline & $9-10$ & 5.8 \\
\hline & More than 10 & 32.9 \\
\hline
\end{tabular}


Figure 1: Timing of Training

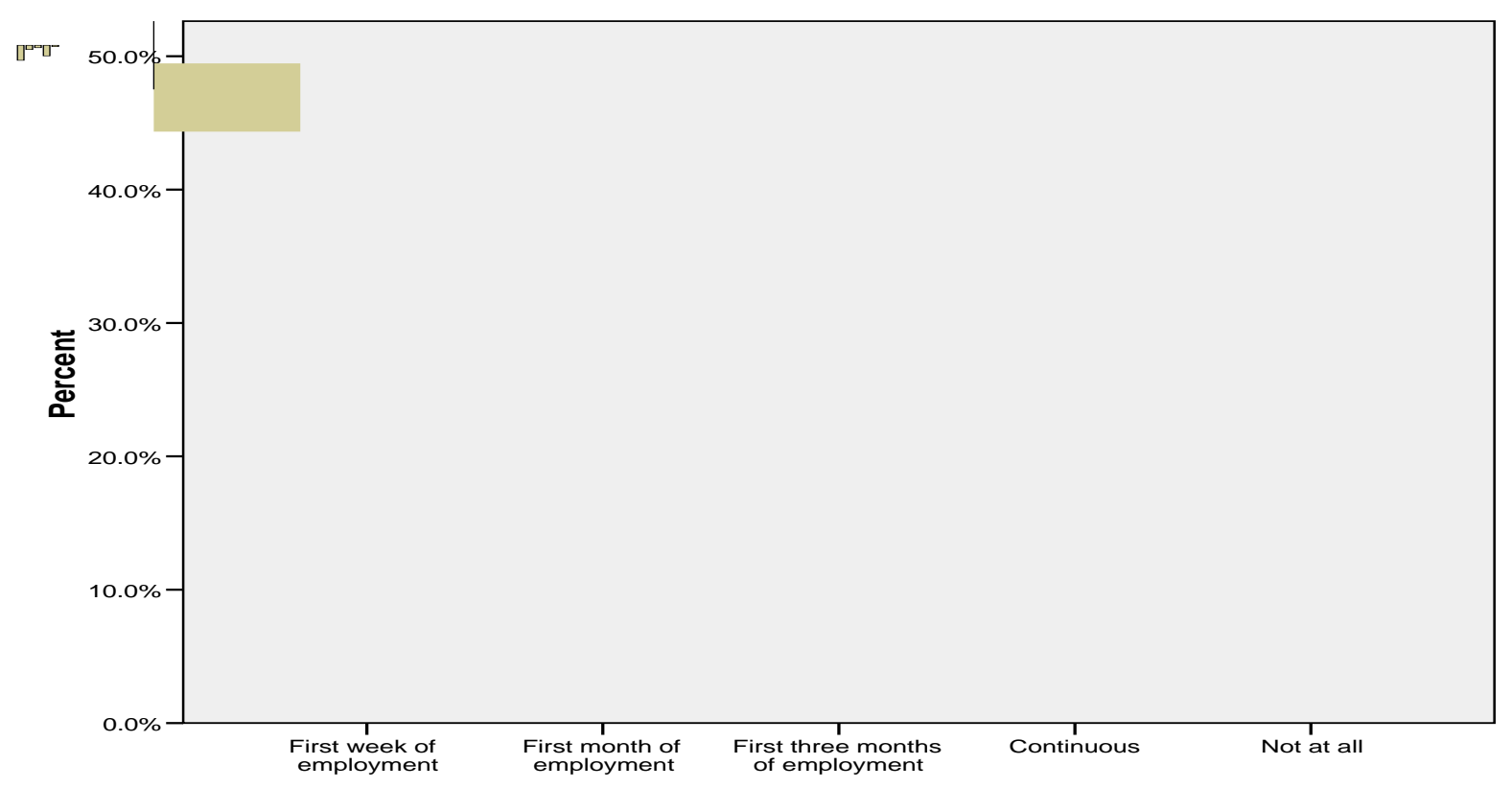




\section{Table 2: Access to Training Programs (\%)}

Off-the-job training Training provided by organisation during work time

71.9

Training provided by organisation outside work time

Study outside organisation during work time (fees paid by company)

Training outside organisation during work time (fees reimbursed by company)

Training outside organisation during non-work time (fees reimbursed by company)

Training programs

Induction and orientation

Occupational skills

Technical/professional

Management development for administrative staff

Behavioural training (eg. organisational values,

Note. Multiple response questions. Percentages do not sum to 100 within categories 
Table 3: Perceived Effectiveness of Training Practices (\%)

\begin{tabular}{|c|c|c|c|c|c|c|c|}
\hline & Not at a & $\rightarrow$ & Moderately & $\rightarrow$ & To a great extent & Mean & SD \\
\hline Provide me with an increase in salary & 52.3 & 14.1 & 20.9 & 7.5 & 5.2 & 1.99 & 1.23 \\
\hline Provide me with promotion to higher levels & 36.2 & 7.9 & 31.9 & 8.5 & 5.5 & 2.29 & 1.20 \\
\hline Improve my technical job abilities & 6.8 & 8.5 & 40.4 & 23.1 & 21.2 & 3.43 & 1.12 \\
\hline Improve my interpersonal abilities & 7.3 & 10.7 & 45.7 & 17.3 & 19.0 & 3.30 & 1.12 \\
\hline Remedies my past poor performance & 29.7 & 14.8 & 40.7 & 4.5 & 10.3 & 2.51 & 1.25 \\
\hline Prepares me for future assignments & 19.7 & 15.1 & 30.8 & 16.1 & 18.4 & 2.98 & 1.36 \\
\hline Builds teamwork within my organisation & 7.6 & 6.3 & 48.7 & 20.5 & 16.9 & 3.33 & 1.07 \\
\hline Provided substantial training when I first started work & 12.5 & 15.7 & 38.0 & 8.5 & 25.2 & 3.18 & 1.31 \\
\hline Helps me to understand the business & 15.4 & 12.7 & 36.6 & 21.6 & 13.7 & 3.06 & 1.23 \\
\hline Provides me the skills needed to do a number of different jobs & 14.1 & 10.5 & 40.3 & 19.7 & 15.4 & 3.12 & 1.21 \\
\hline Teaches me about the organisation's values and practices & 13.1 & 14.7 & 39.2 & 17.6 & 15.4 & 3.08 & 1.21 \\
\hline Prepare me to be more effective at my job & 4.7 & 6.3 & 41.2 & 19.9 & 27.9 & 3.60 & 1.10 \\
\hline Make me feel more confident to undertake my work & 8.3 & 5.6 & 41.1 & 26.5 & 18.5 & 3.41 & 1.11 \\
\hline Keeps me motivated to continue work in this organisation & 7.6 & 13.3 & 36.5 & 17.6 & 24.9 & 3.39 & 1.21 \\
\hline
\end{tabular}


